Article

\title{
Factors Influencing Collaborative Innovation Project Performance: The Case of China
}

\author{
Hong Liu ${ }^{1}$, Zhihua Liu ${ }^{1}$, Yongzeng Lai ${ }^{2}$ and Lin Li ${ }^{1, *}$ \\ 1 Business School, Hunan University, Changsha 410012, China; yijing@hnu.edu.cn (H.L.); \\ 1zh20071833@163.com (Z.L.) \\ 2 Department of Mathematics, Wilfrid Laurier University, Waterloo, ON N2L 3C5, Canada; ylai@wlu.ca \\ * Correspondence: li2518@hnu.edu.cn
}

Citation: Liu, H.; Liu, Z.; Lai, Y.; Li, L. Factors Influencing Collaborative Innovation Project Performance: The Case of China. Sustainability 2021, 13, 7380. https://doi.org/10.3390/ su13137380

Academic Editor: António Abreu

Received: 23 May 2021

Accepted: 29 June 2021

Published: 1 July 2021

Publisher's Note: MDPI stays neutral with regard to jurisdictional claims in published maps and institutional affiliations.

Copyright: (c) 2021 by the authors. Licensee MDPI, Basel, Switzerland. This article is an open access article distributed under the terms and conditions of the Creative Commons Attribution (CC BY) license (https:// creativecommons.org/licenses/by/ $4.0 /)$.

\begin{abstract}
This study conducted a comprehensive and systematic investigation of the influencing factors for collaborative innovation project (CIP) performance. First, a theoretical framework model was constructed, and then a structural equation model (SEM) was used for an empirical analysis of 199 CIPs. Furthermore, we divided the factors into tangible and intangible categories and considered the impact mechanism of nine typical factors on project performance. The results are as follows: (1) All nine factors had a significant positive impact on the performance of collaborative innovation projects, among which benefit distribution and collaborative innovation capability were the most important. (2) Benefit distribution, resource dependence, organizational climate, and collaborative innovation affected project performance, both directly and indirectly. (3) Effective communication, leadership support, knowledge sharing, and collaborative innovation ability only had a direct influence, while the incentive mechanism played only an indirect role. Finally, three suggestions were put forward on the idea of high-quality, sustainable development.
\end{abstract}

Keywords: collaborative innovation project; sustainable development; project performance; influencing factors; SEM

\section{Introduction}

University-industry cooperation (UIC) first appeared in the Chinese Government Work Statement (GOV.CN WS) in 1999, and it was adjusted to university-industry cooperation innovation (UICI) in 2014. To date, 17 years' worth of data has been reported in the GOV.CN WS, which clearly shows that we should pay attention to it. From the time, frequency, and subsequent changes of words appearing in the GOV.CN WS, we can generally judge the trend of China's economic development pattern and its importance and evolution in national economic and social development. China has entered a new stage of promoting sustainable and high-quality development. At the microlevel, sustainable and high-quality development relies on innovation to enhance the vitality and competitiveness of economic entities and ensure the significant improvement of economic efficiency [1].

According to the bulletin of China's national economic and social statistics, the turnover of granted patents and technology contracts in China increased by 31.9 and 35.32 times, respectively, in the 20 years from 2001 to 2020 [2]. The collaborative innovation of UIC is one of the main forms of the transformation of scientific and technological achievements in the country, which is also the key to radical innovation in firms [3]. The UIC has developed vigorously in practice. Therefore, it is imperative to promote its development towards being of high quality.

The organization of UICI is achieved through the university-industry collaborative innovation project (UICIP). A collaborative innovation project (CIP) is a kind of project in which enterprises cooperate with universities, research institutes, and other enterprises to develop new technologies and processes [4]. In addition to the main form of the UICIP, there are also different forms of cooperation between universities and colleges, universities 
and research institutes, and enterprises and enterprises. Wu et al. [5] described cooperative innovation projects as specific projects in which companies and public research institutions or other companies cooperate to create new technologies, products, materials, systems, or manufacturing processes.

The environment of science and technology innovation in China and abroad is changing rapidly and is complex. This will lead to increased uncertainty about the sustainable development of CIP. Therefore, how to ensure the sustainable development of CIPs and how to improve their performance are worthy of further study. In the past, most studies have focused on the impact of a single factor on collaborative innovation performance. These studies on single or few factors are of great significance to understand some problems of performance factors. However, they cannot be extended to a comprehensive and systematic analysis. Hence, there is a lack of systematic and comprehensive research on the influencing factors of performance. This study makes up for this deficiency by comprehensively and systematically investigating these factors to ensure the sustainable development of CIP and improve its performance. Specifically, the main contents and structure of this manuscript are as follows. A literature review is given in Section 2 . The research hypotheses and conceptual model are presented in Section 3. The research design is described in Section 4. An empirical study using structural equation model hypothesis testing is described in Section 5. The conclusion and future work are presented in Section 6.

\section{Literature Review}

UIC may be the most important strategic instrument used to increase the efficiency and effectiveness of industrial investments in $R \& D$, and increasing use makes it more important to figure out the factors that influence its performance [6]. After searching the existing relevant literature, we found that research on the influencing factors of collaborative innovation project performance mainly focuses on two aspects.

\subsection{Literature Review on Tangible Influencing Factors of Collaborative Innovation Project Performance (CIPP)}

One aspect of collaborative innovation project performance is focused on tangible factors.

López [7] conducted a study based on data collected through semi-structured interviews between January and October 2009, with a sample of 375 firms in three countries, that indicated that different companies have different innovation capabilities, and more innovative firms tend to be more interested in collaborating with universities. At the same time, high-tech and non-high-tech firms have different attitudes and intentions around collaborating with universities. Kafouros et al.'s [8] research showed that absorptive capacity has a significant impact on innovation performance, but the degrees of significance are different in different cooperative relationships.

Azagracaro et al.'s [9] research showed that innovation capability is affected by the relationship and cooperation mode of collaborative innovation project subjects. He et al.'s [10] research noted that characterizing leadership is important for revealing the interaction pattern and organizational structure through research collaboration. Fernandes et al. [11] showed that leadership support is important for the sustainable development of UIC. Benefits are key for university-industry collaborative innovation to maintain a long-term stable relationship [12], while benefit distribution positively affects the performance of collaborative innovation and can improve efficiency by influencing the incentive mechanism [12]. At the same time, the most critical factors for the realization of benefits are strategic, inter-relational, and cultural factors [13].

From the above analysis, we can see that research on the tangible influencing factors of collaborative innovation project performance mainly focuses on collaborative innovation ability, willingness to cooperate, leadership support, benefit creation, and benefit distribution. 


\subsection{Literature Review on Intangible Influencing Factors of Collaborative Innovation Project Performance (CIPP)}

The other aspect of collaborative innovation project performance is focused on intangible factors.

Freitas [14] relied on in-depth data on 30 university-industry collaborations in the Netherlands and provided preliminary evidence that effective cooperation in UICs can create institutional incentives by targeting different individual motivations. Maurer [15] found that trust between project team members working on an inter-organizational project positively impacts the acquisition of external knowledge, which, in turn, promotes product innovation. Both universities and industries in the process of UIC need to overcome high cultural and organizational barriers in order to realize their potential [16].

Managers may engage in a social process of communication, both formal and informal [17], to engender trust between partners, and communication can also reduce the negative effects of information asymmetry in alliances [14]. Wu [18] studied cooperative knowledge transfer and governance mechanisms with regard to how to influence cooperative innovation performance using a sample of 238 projects with SEM. Using firm-level data on 263 firms in Korea, Han [19] found that knowledge sharing in UICs is likely related to the managerial strategies of CEOs rather than other team members.

Knowledge sharing in UICs has different effects on innovation performance through forming different areas [20], where it presents a core-edge spatial pattern [6]. Based on a historical analysis of UICs in Japan, Lee et al. [21] found that different types of UICs require functional specialization in boundary-spanning organizations by developing coordinative expertise, human resources, institutional arrangements, and organizational structures. When a university is heavily reliant on industry funding, it leads to the close co-evolution of UICs, thereby raising the risk of a mutual lock-in regarding specific technologies, which is good for collaborative innovation project performance [22].

From the above analysis, we can see that research on the intangible influencing factors of collaborative innovation project performance mainly focuses on incentive systems, the organizational atmosphere, effective communication, knowledge transfer, knowledge absorption, and resource dependence.

The above studies are very helpful for understanding and improving collaborative innovation project performance. However, all of them have investigated the influencing factors from a single perspective; as such, there is a lack of comprehensive and systematic research on the influencing factors. This study intends to make up for this deficiency. It summarizes the typical tangible and intangible factors that affect the performance of collaborative innovation projects and conducts comprehensive and systematic research.

Specifically, this study explores the specific impact mechanism of nine factors on the performance of collaborative innovation projects based on existing research. It includes four typical tangible factors (collaborative innovation ability, leadership support, incentive mechanism, and benefit distribution) and five typical intangible factors (knowledge sharing degree, effective communication, collaborative innovation willingness, resource dependence, and organizational climate). It also puts forward hypotheses on influencing factors and collaborative innovation project performance by using SEM to do empirical research with data from a questionnaire survey. Obviously, this study has important theoretical and practical significance toward deepening the research on the factors that impact collaborative innovation project performance.

\section{Research Hypotheses and Conceptual Model}

Based on the collaborative innovation project process and the existing literature, this paper summarizes the influencing factors as tangible and intangible factors. The tangible factors are collaborative innovation ability, leadership support, incentive mechanism, and benefit distribution. The intangible factors are knowledge sharing, effective communication, collaborative innovation willingness, resource dependence, and organizational climate. 
According to the relevant research and the influence path characteristics of various factors with regard to project performance, these factors can be divided into those with a direct impact, indirect impact, and a combination of the two. The details are as follows.

\subsection{Collaborative Innovation Project Performance (CIPP)}

The Project Management Institute (PMI) claims that project success should balance the competitive demand for project quality, scope, time, and cost; address the different concerns; and meet the expectations of project stakeholders [23]. This is to satisfy the stakeholders. For collaborative innovation projects, project stakeholders are the main body of collaborative innovation.

In short, the connotation of project performance includes the overall satisfaction of collaborative innovation, quality performance, and cost performance of the results.

\subsection{Influencing Factors and CIPP}

\subsubsection{Collaborative Innovation Ability and CIPP}

Innovation ability is an important criterion for measuring the comprehensive competitiveness of a country or region [24]. Collaborative innovation capability is the foundation of collaborative innovation projects. Different subjects will have different innovation choices based on their own collaborative innovation capabilities [7]. Collaborative innovation ability is the key to success for complex cross-level, cross-sectoral, and cross-regional projects and can significantly improve the overall capacity of inter-subject collaboration [25]. Hong [26] found that absorptive capacity has a significant positive effect on innovation performance. Zhang [27] studied how to improve collaborative innovation ability and pointed out that providing support in terms of funds, policies, and so on could promote the improvement of such capabilities. Collaborative innovation capability has a significant impact on collaborative innovation performance [28]. Tseng [29] analyzed influential factors and concluded that an enterprise's technology ability has a direct impact on its cooperative innovation performance, showing that there is a positive correlation between the absorptive capacity of internal $\mathrm{R} \& \mathrm{D}$ and project performance. Since the performance of collaborative innovation projects mainly includes innovation performance [30], we propose the following hypothesis:

Hypothesis 1 (H1). Project collaborative innovation ability has a significant positive correlation with the performance of collaborative innovation projects.

\subsubsection{Knowledge Sharing and CIPP}

Collins and Smith [31] described knowledge sharing as access to knowledge innovation for teams, which is very important for improving innovation performance. Pang [32] did an empirical study with SEM, where the results showed that knowledge sharing can significantly affect the satisfaction of participants. Knowledge sharing has different sharing mechanisms in different teams [33]. Doan [34] empirically studied the relationship between knowledge sharing and innovation performance, where the results showed that both explicit and tacit knowledge sharing have a positive effect on firm performance. Rahmi [35] showed that cognitive diversity has a significant association with knowledge sharing, and knowledge sharing is positively associated with team innovation. Than's [36] study using 225 samples in Vietnam also showed that knowledge sharing, directly and indirectly, affects firm performance.

Therefore, we propose the following hypothesis:

Hypothesis 2 (H2). Project knowledge sharing has a significant positive correlation with the performance of collaborative innovation projects. 


\subsubsection{Leadership Support and CIPP}

Pirola-Merlo [37] proposed that support from senior management is an important factor for the success of innovation activity. A survey of 289 project managers of public sector projects in Pakistan showed that project managers' leadership plays an important role in improving project performance. Leadership is embodied in schedule, cost, quality, and stakeholder satisfaction and is significantly related to the achievement of project performance [38]. Project research in Jordan showed that communication management, human resource management, time management, and risk management ability of project leaders have an impact on project performance [17]. Pham [39] studied the impact of leadership support on sustainable development performance. The results showed that leadership can affect performance by strengthening the relationship between environmental practice and sustainable development.

Therefore, we propose the following hypothesis:

Hypothesis 3 (H3). Leadership support has a significant positive correlation with the performance of collaborative innovation projects.

\subsubsection{Effective Communication and CIPP}

Kamuriwo [17] indicated that communication can reduce uncertainty in the process of cooperation, which is useful for ensuring the close relationship of cooperation and has positive significance for the realization of the organization. Bstieler [40] showed that the degree of trust between subjects can affect innovation performance by regulating communication and decision-making between them. Schreiner [41] showed that the closer the relationships are between all parties, the higher the cooperation performance. Adiguzel [42] showed that leadership effectiveness and learning orientation have a positive impact on effective communication, team creativity, and service innovation. Iswanti [43] showed that leaders' effective communication contributes to the development of an organizational innovation culture, and whether leaders can communicate effectively is influenced by leadership characteristics.

Therefore, we propose the following hypothesis:

Hypothesis 4 (H4). Effective communication has a significant positive correlation with the performance of collaborative innovation projects.

\subsubsection{Incentive Mechanism and CIPP}

Bruneel [44] noted that incentives were useful for motivating knowledge workers to share knowledge in order to improve the efficiency of knowledge innovation activities; otherwise, employees would keep the knowledge to themselves. He [45] employed the quantum game paradigm to study the incentive mechanism of industry-universityinstitute (IUI) collaborative innovation and found that a quantum strategy with maximal effort is the most profitable. Xiong [46] pointed out that it is very difficult for members to actively share knowledge of innovation failure without incentives, and this type of knowledge sharing plays an important role in reducing the probability of repeated failure and improving the innovation ability of virtual research organizations.

$\mathrm{Wu}$ [47] showed that different government incentive mechanisms have an impact on enterprises and universities. Government policy support is more attractive to enterprises, and financial support has a greater impact on universities.

Therefore, we propose the following hypothesis:

Hypothesis $\mathbf{5}$ (H5). The incentive mechanism has a significant positive correlation with collaborative innovation intention. 


\subsubsection{Collaborative Innovation Willingness and CIPP}

Collaborative innovation willingness is a kind of driving factor that reflects the coordinators' emphasis on collaborative innovation and willingness. A study based on data collected from 375 companies in Spain, Portugal, and France through semi-structured interviews showed that more innovative enterprises tend to cooperate with universities. At the same time, national factors also affect the willingness of enterprises to cooperate with universities [7]. Vaaland [48] noted that in complex innovation projects, whether the cooperative intention of an external innovation source is positive or not will greatly affect innovation performance.

Gendreau [49] showed that collaborative innovation willingness and innovation ability can affect performance by influencing the knowledge absorptive capacity. The willingness to participate in cooperative innovation is positively influenced by organizational atmosphere and system design [50]. Members will show different levels of innovation willingness at different innovation stages [51]. The members of UICs have different levels of willingness to innovate. The willingness of enterprises is most easily affected by market behavior, while the willingness of universities is more easily affected by the willingness of the government [47].

Therefore, we propose the following hypotheses:

Hypothesis 6 (H6). Collaborative innovation has a significant positive correlation with the performance of collaborative innovation projects.

Hypothesis 7 (H7). Collaborative innovation has a significant positive correlation with knowledge sharing.

\subsubsection{Resource Dependence and CIPP}

The relationship between resource dependence and economically sustainable growth is U-shaped [52]. Resource dependence establishes the boundary of knowledge management, and good knowledge management ability is beneficial to organizational performance [53]. Nijhof [54] pointed out that cooperation must be established on the basis of mutual dependence. Narula [55] analyzed innovation cooperation in Japan and Europe and concluded that obtaining complementary knowledge was one of the most important goals to achieve when building government funding for innovation cooperation. Therefore, one of the motives for launching a collaborative innovation project is collaborative resource interdependence and the complementarity of economic activities among collaborative innovators. Moreover, when the parties are more desirous of scarce resources, they will be more willing to engage in collaborative innovation.

Therefore, we propose the following hypotheses:

Hypothesis 8 (H8). Resource dependency has a significant positive correlation with collaborative innovation willingness.

Hypothesis 9 (H9). Resource dependency has a significant positive correlation with the performance of collaborative innovation projects.

\subsubsection{Benefit Distribution and CIPP}

The pursuit of interests is the main goal of collaborators, but the pursuit of selfinterest cannot be at the cost of damage to the interests of others; otherwise, it will lead to the failure of collaboration. In the process of collaborative innovation, the collaborative units invest their effort and should get corresponding returns. Sivadas [56] pointed out that the complexities of interest relations, the differences in organization unit goals, and the lack of a constraint mechanism will inevitably lead to a conflict of interest between organizations, which causes instability and failure. Establishing an appropriate and clear benefit distribution mechanism can guarantee successful collaborative innovation. 
Berbegal [57] pointed out that effectively coordinating the distribution of interests is the key to guaranteeing a "win-win" scenario before launching innovation cooperation activities.

$\mathrm{Li}$ [58] showed that according to the different needs of alliance members, the benefit distribution model can fully encourage members to participate in collaborative innovation and improve project performance.

A reasonable distribution of interests will not only meet the needs of individuals but can also optimize the overall interests [59]. At the same time, it can also improve the willingness to innovate, which has a positive role in promoting environmental and economic development [60].

Therefore, we propose the following hypotheses:

Hypothesis 10 (H10). Benefit distribution has a significant positive correlation with the willingness to engage in collaborative innovation.

Hypothesis 11 (H11). Benefit distribution has a significant positive correlation with the performance of collaborative innovation projects.

\subsubsection{Organizational Climate and CIPP}

Collins [31] found that it was very important to create a team atmosphere with positive attitudes and knowledge sharing, which are important factors that affect knowledge sharing. Huang [61] argued that an environment of trust has a great role in promoting positive and spontaneous knowledge sharing. Steinmo [62] found that the innovation atmosphere of R\&D teams has a very significant influence on the teams' innovation performance. Pirola [37] studied the impact of team climate on the speed of research and development project completion with a sample of $33 \mathrm{R} \& \mathrm{D}$ teams and showed that team climate was significantly correlated with project performance. $\mathrm{Xu}$ [63] explored the influence of team innovation climate on individual and team innovation performance. The research showed that the team innovation climate can stimulate individual innovation intentions, which can benefit innovation performance. Rahmi [35] showed that team climate moderates the relationship between cognitive diversity and knowledge sharing.

Therefore, we propose the following hypotheses:

Hypothesis 12 (H12). The organizational climate has a significant positive correlation with knowledge sharing.

Hypothesis 13 (H13). The organizational climate has a significant positive correlation with the performance of collaborative innovation projects.

\subsection{Conceptual Model}

By dividing the influencing factors into tangible and intangible factors, this paper comprehensively and systematically discusses how these factors affect collaborative innovation project performance. Based on the above analysis, a conceptual model was established. Figure 1 shows the conceptual framework and theoretical relationships between the nine factors and collaborative innovation project performance. 


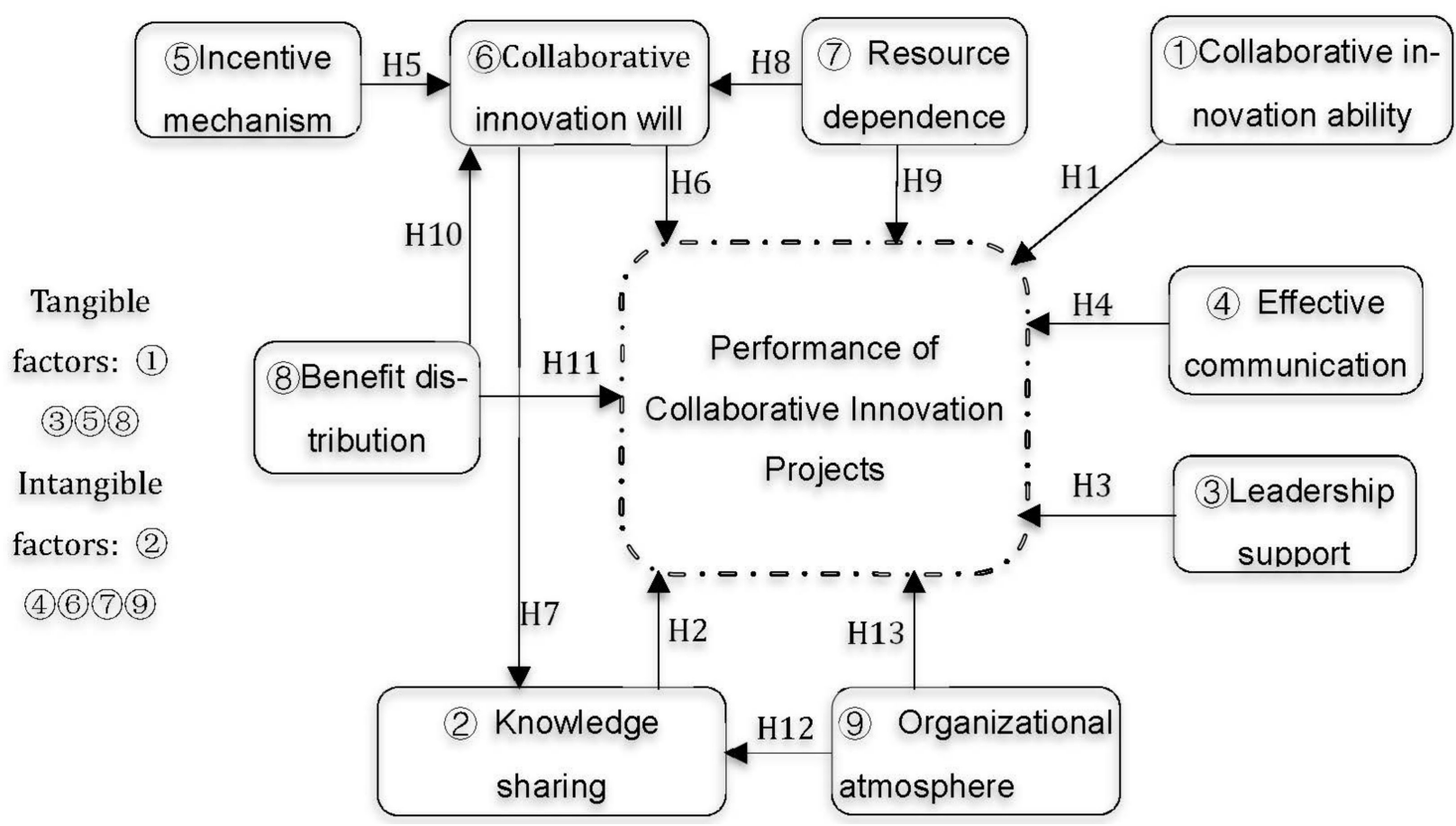

Figure 1. Conceptual framework.

\section{Research Design}

\subsection{Questionnaire Design and Data Collection}

For this study, we obtained the data needed for demonstration through a large-scale questionnaire survey. In the process of distributing the questionnaire, we tried to control the channel of distribution and screen the fillers in order to exclude the influence of external factors on the results.

The subjects of the questionnaire were individuals who were carrying out or had carried out collaborative innovation projects. Those who filled in the form were workers in government departments of science and technology, the R\&D staff of enterprises, the scientific research staff at universities and research institutions, and the staff of a science and technology intermediary agency.

To distribute the questionnaire, we first implemented the survey in a digital format through the Questionnaire Star network platform (http:/ / www.wjx.cn/jq/2761389.aspx) (accessed on 4 March 2021) and then sent it to those who met our requirements. A total of 290 questionnaires were sent out, 211 were returned, and 199 were filled out appropriately. The effective recovery rate was $68.6 \%$.

The descriptive statistics of the characteristics of the sample projects are shown in Table 1 and Figure 2. These projects were relatively evenly distributed among provinces, occupations, academic disciplines, and works in the innovation research/working time, which could appropriately reflect the comprehensive situation of domestic collaborative innovation projects. 
Table 1. Descriptive characteristics of respondents.

\begin{tabular}{|c|c|c|c|}
\hline & Project Category & Number & Percentage \\
\hline \multirow{5}{*}{ Occupation } & $\begin{array}{c}\text { Workers in government science and technology } \\
\text { departments }\end{array}$ & 24 & $12.06 \%$ \\
\hline & Scientific researchers at colleges and universities & 68 & $34.18 \%$ \\
\hline & R\&D personnel of enterprises & 49 & $24.62 \%$ \\
\hline & Researchers at research institutes & 37 & $18.59 \%$ \\
\hline & $\begin{array}{l}\text { Personnel of science and technology } \\
\text { intermediaries }\end{array}$ & 21 & $10.55 \%$ \\
\hline \multirow{4}{*}{ Educational background } & Doctorate & 57 & $28.64 \%$ \\
\hline & Master's & 75 & $37.69 \%$ \\
\hline & Undergraduate & 38 & $19.10 \%$ \\
\hline & Junior college or below & 29 & $14.57 \%$ \\
\hline \multirow{5}{*}{ Length of relevant work } & Within 1 year & 18 & $9.03 \%$ \\
\hline & $1-3$ years & 78 & $39.20 \%$ \\
\hline & $3-5$ years & 39 & $19.60 \%$ \\
\hline & $5-10$ years & 30 & $15.08 \%$ \\
\hline & More than 10 years & 34 & $17.09 \%$ \\
\hline
\end{tabular}

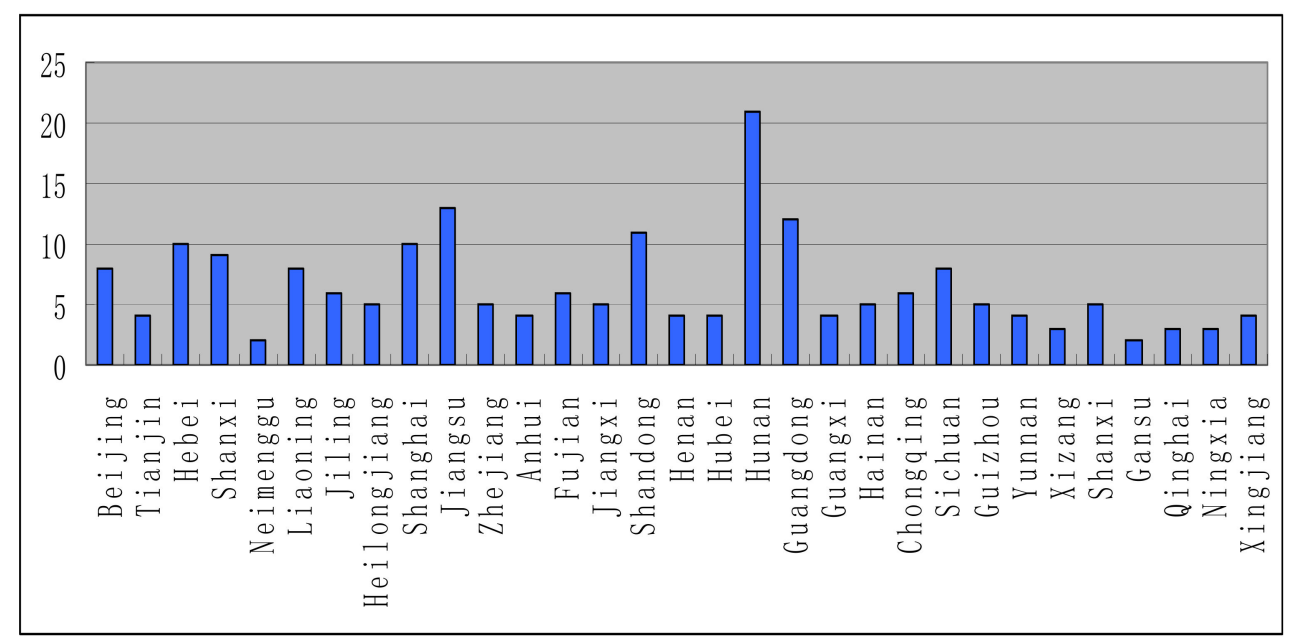

Figure 2. Province distribution of questionnaire respondents.

\subsection{Variable Measurement}

To meet the principle of representativeness and validity of research samples and to remain in line with the research theme, we referred to the mature scale and consulted experts and scholars in this field. According to the feedback from pilot interviews and a questionnaire survey, we produced the final questionnaire. The specific process was as follows:

First, we read foreign literature to obtain the relevant variables.

Second, we asked government, university, research institution, and technology enterprise agency experts to add comments on the questionnaire design through field research.

Third, we formed an initial version of the questionnaire according to the suggestions from the relevant research experts.

Finally, we tested the questionnaire by using small-scale samples. tionnaire.

According to the testing results, we made improvements and formed the final ques-

The final questionnaire used a 5-level Likert system, asking respondents to rank their answers as 1,3,5,7, or 9 based on their actual condition. The items included collaborative innovation project performance and intangible and tangible factors.

The dependent and independent variables were as follows: 
(1) The dependent variable was collaborative innovation project performance. Based on the relevant research [23], this study comprehensively measured such performance based on satisfaction of the subject, project quality performance, and cost performance.

(2) The independent variables were four tangible factors and five intangible factors. Based on the existing research, the four tangible factors were collaborative innovation ability [7], leadership support [8], incentive mechanism [46], and benefit distribution [56]. The five intangible factors were knowledge sharing [31], effective communication [17], collaborative innovation willingness [48], resource dependence [54], and organizational climate [31].

\subsection{Research Method}

This study explored the impact mechanism of various tangible and intangible factors on collaborative innovation project performance in order to verify the relationship between multiple independent variables (latent variables) and a dependent variable (latent variable). The structural equation model (SEM) method is a multivariate analysis method that is used to verify the relationship between one or more independent variables (latent variables) and one or more dependent variables (latent variables) and has the ability to deal with the unobservable hypothesis concepts in the model. Based on studies by Al-Refaie [64] and Wen [65], we used structural equation modeling to carry out the study. Using AMOS software to analyze the SEM, we could judge whether the original hypotheses were tenable and determine the specific relationships between variables through the overall fitness of the model, significance levels, path coefficients, and so on.

\section{Empirical Study}

\subsection{Reliability and Validity Analysis}

Using SPSS statistical software, we analyzed the reliability and validity of the questionnaire with Cronbach's alpha and KMO factor analysis, respectively; the Cronbach's alpha values for each variable were greater than 0.7 , indicating good reliability, while the $\mathrm{KMO}$ values were higher than 0.6 , indicating high validity (Table 2).

Table 2. Reliability and validity of the questionnaire.

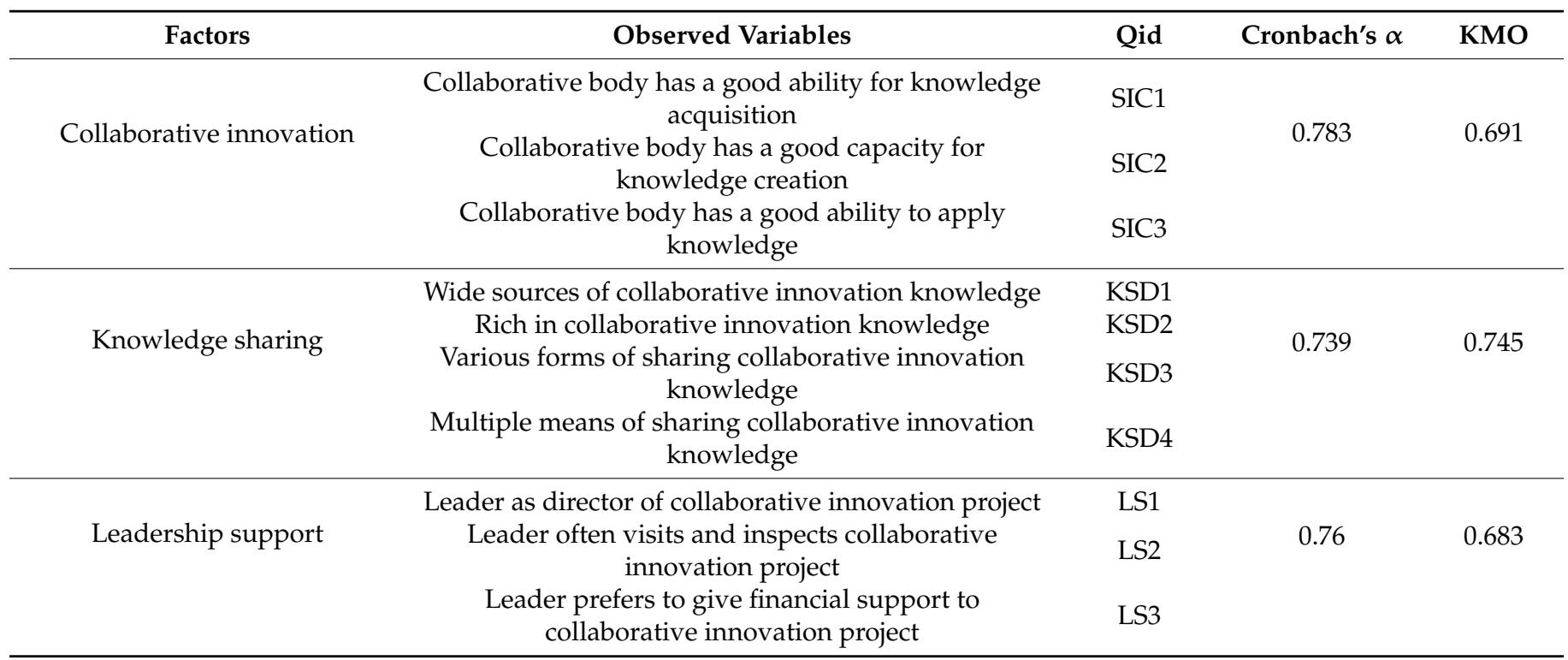


Table 2. Cont.

\begin{tabular}{|c|c|c|c|c|}
\hline Factors & Observed Variables & Qid & Cronbach's $\alpha$ & KMO \\
\hline \multirow{4}{*}{ Effective communication } & $\begin{array}{l}\text { Main staff members can maintain regular } \\
\text { communication }\end{array}$ & EC1 & \multirow{4}{*}{0.721} & \multirow{4}{*}{0.781} \\
\hline & $\begin{array}{l}\text { Main technical staff members regularly participate in } \\
\text { meetings to deal with problems }\end{array}$ & EC2 & & \\
\hline & $\begin{array}{l}\text { Synergy between main regular formal meetings and } \\
\text { formal document delivery }\end{array}$ & EC3 & & \\
\hline & $\begin{array}{l}\text { Synergy between main regular site visits and visits to } \\
\text { other units }\end{array}$ & EC4 & & \\
\hline \multirow{2}{*}{ Incentive mechanism } & Diverse collaborative incentives with complementary & EM1 & \multirow{2}{*}{0.832} & \multirow{2}{*}{0.618} \\
\hline & Collaborative incentives are implemented & EM2 & & \\
\hline \multirow{2}{*}{$\begin{array}{l}\text { Collaborative innovation } \\
\text { willingness }\end{array}$} & $\begin{array}{l}\text { Main emphasis on collaboration and creating } \\
\text { conditions for collaborative innovation }\end{array}$ & SIW1 & \multirow[t]{2}{*}{0.806} & \multirow[t]{2}{*}{0.652} \\
\hline & $\begin{array}{l}\text { Main emphasis on collaboration and coordination } \\
\text { involved in the collaborative innovation process }\end{array}$ & SIW2 & & \\
\hline \multirow{3}{*}{ Resource dependence } & $\begin{array}{c}\text { Collaborative partners depend on their own valuable } \\
\text { resources }\end{array}$ & RD1 & \multirow{3}{*}{0.743} & \multirow{3}{*}{0.695} \\
\hline & $\begin{array}{c}\text { Collaborative partners depend on resources they } \\
\text { cannot imitate }\end{array}$ & RD2 & & \\
\hline & $\begin{array}{l}\text { Collaborative partners can supplement their own } \\
\text { resources }\end{array}$ & RD3 & & \\
\hline \multirow{4}{*}{ Benefit distribution } & Fair distribution of benefits & BD1 & \multirow{4}{*}{0.704} & \multirow{4}{*}{0.778} \\
\hline & $\begin{array}{l}\text { Collaboration between diverse interests within the } \\
\text { main distribution network }\end{array}$ & $\mathrm{BD} 2$ & & \\
\hline & $\begin{array}{l}\text { Coordinating bodies have clear self-interest and } \\
\text { common interests }\end{array}$ & BD3 & & \\
\hline & $\begin{array}{l}\text { Coordinating bodies have formal distribution } \\
\text { agreement(s) }\end{array}$ & BD4 & & \\
\hline \multirow{4}{*}{ Organizational climate } & $\begin{array}{c}\text { Collaborative bodies can recognize and accept their } \\
\text { differences }\end{array}$ & OC1 & \multirow{4}{*}{0.718} & \multirow{4}{*}{0.762} \\
\hline & $\begin{array}{l}\text { Collaborative bodies agree to acquire knowledge of } \\
\text { one another's value }\end{array}$ & OC2 & & \\
\hline & $\begin{array}{c}\text { Collaborative bodies trust each other to provide } \\
\text { authentic information }\end{array}$ & OC3 & & \\
\hline & $\begin{array}{l}\text { Collaborative bodies can actively learn during the } \\
\text { collaborative innovation process }\end{array}$ & OC4 & & \\
\hline \multirow{4}{*}{$\begin{array}{l}\text { Collaborative innovation } \\
\text { project performance }\end{array}$} & $\begin{array}{l}\text { Collaborative bodies invest labor and funds and } \\
\text { establish good infrastructural, cultural, and } \\
\text { institutional environments }\end{array}$ & SCP1 & \multirow{4}{*}{0.735} & \multirow{4}{*}{0.786} \\
\hline & $\begin{array}{c}\text { Collaborative bodies have good communication } \\
\text { processes and cooperative practices }\end{array}$ & SCP2 & & \\
\hline & $\begin{array}{l}\text { Collaborative bodies have good collaborative } \\
\text { innovation income }\end{array}$ & SCP3 & & \\
\hline & $\begin{array}{l}\text { Results of collaborative innovation projects have } \\
\text { good economic and social impact }\end{array}$ & SCP4 & & \\
\hline
\end{tabular}

\subsection{Common Method Bias}

The data were from a questionnaire survey, which may lead to common method bias.

According to the research conclusion of Podsakoff [66], there are two ways to overcome and test common method bias: program control and statistical control.

In terms of procedure control, common method deviation was controlled in the questionnaire design and collection stage. This mainly included: (1) assuring that all the information collected would only be used for academic research, not for other purposes, and (2) repeatedly revising the items and wording of the questionnaire with reference 
to the mature scale and in consultation with experienced experts in order to eliminate misunderstanding.

For statistical control, the Harman single-factor test was used. Harman univariate analysis was performed in the SPSS software. The result of the analysis showed that the explained percentage of the variance of the first common factor was 0.33 , which is lower than the judgment standard of 0.50 . Therefore, it can be considered that there was no obvious common method deviation in this study.

\subsection{Hypothesis Testing Using a Structural Equation Model (SEM) \\ 5.3.1. Model Fitting}

This study used an SEM to verify the theoretical model with AMOS 17.0 software. There were 10 potential variables in the theoretical model: collaborative innovation, knowledge sharing, leadership support, effective communication, incentive mechanism, collaborative innovation willingness, resource dependence, benefit distribution, organizational climate, and collaborative innovation project performance. There were 33 observable variables: SIC1, SIC2, SIC3; KSD1, KSD2, KSD3, KSD4; LS1, LS2, LS3; EC1, EC2, EC3, EC4; EM1, EM2; SIW1, SIW2; RD1, RD2, RD3; BD1, BD2, BD3, BD4; OC1, OC2, OC3, OC4; and SCP1, SCP2, SCP3, SCP4. The specific content is shown in Figure 3.

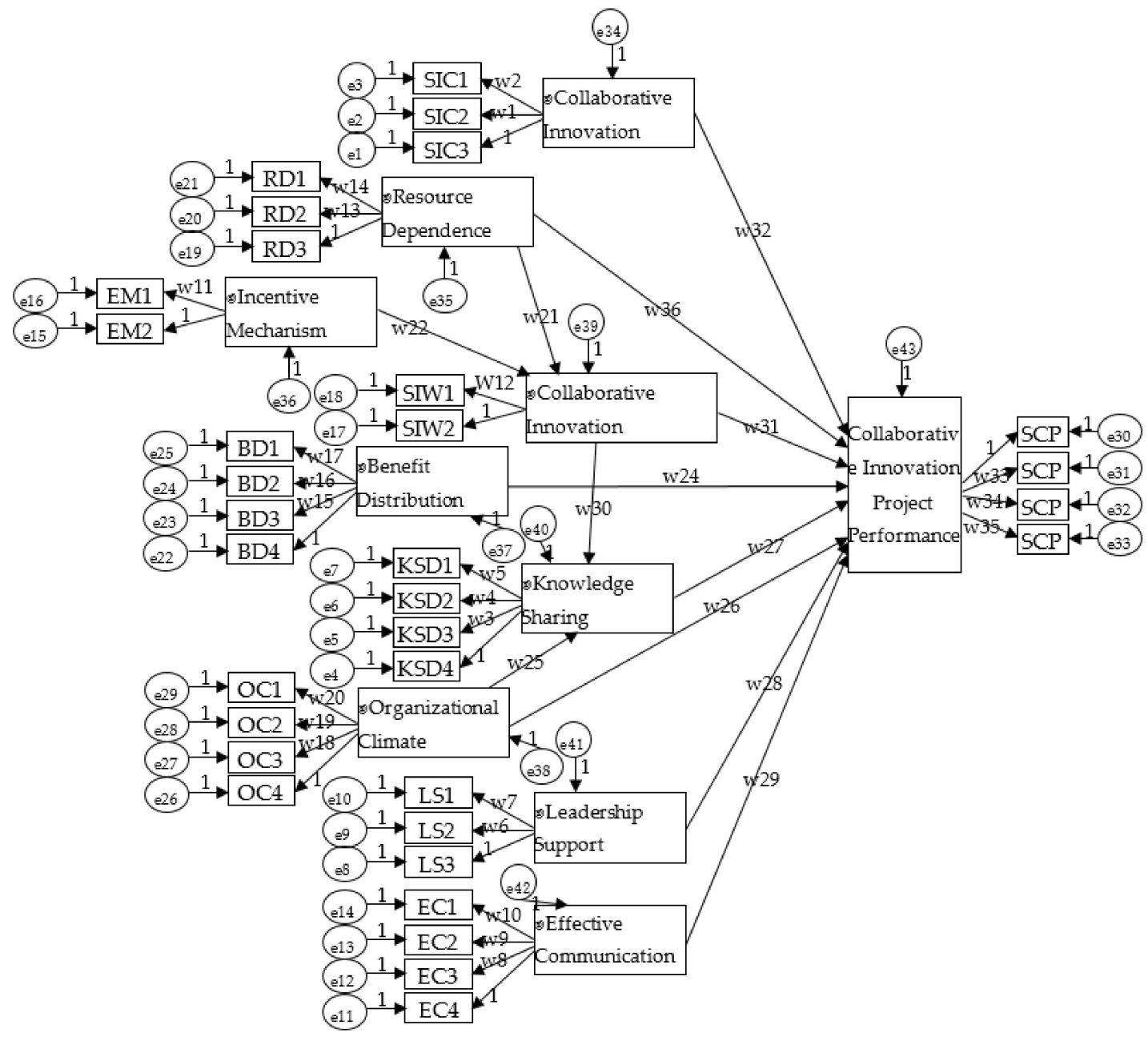

Figure 3. SEM of influencing factors of collaborative innovation project performance.

This study adopted the maximum likelihood method to estimate the model parameters with AMOS software, and the relevant results of the parameter estimation and fitting index of the model are shown in Table 3. 
Table 3. Parameter estimation results.

\begin{tabular}{|c|c|c|c|c|c|c|c|}
\hline & & & Estimate & S.E. & C.R. & $p$ & Label \\
\hline $\begin{array}{c}\text { Collaborative } \\
\text { innovation willingness }\end{array}$ & $\leftarrow$ & Resource dependence & 0.199 & 0.034 & 5.783 & $* * *$ & W21 \\
\hline $\begin{array}{l}\text { Collaborative } \\
\text { innovation willingness }\end{array}$ & $\leftarrow$ & Incentive mechanism & 0.237 & 0.03 & 7.944 & $* * *$ & W22 \\
\hline $\begin{array}{l}\text { Collaborative } \\
\text { innovation willingness }\end{array}$ & $\leftarrow$ & Benefit distribution & 0.952 & 0.051 & 18.72 & $* * *$ & W23 \\
\hline Knowledge sharing & $\leftarrow$ & Organizational climate & 1.269 & 0.169 & 7.486 & $* * *$ & W25 \\
\hline Knowledge sharing & $\leftarrow$ & $\begin{array}{c}\text { Collaborative innovation } \\
\text { willingness }\end{array}$ & 0.022 & 0.009 & 2.415 & 0.016 & W30 \\
\hline CIPP & $\leftarrow$ & Benefit distribution & 0.545 & 0.027 & 20.013 & $* * *$ & W24 \\
\hline CIPP & $\leftarrow$ & Organizational climate & 0.097 & 0.017 & 5.763 & $* * *$ & W26 \\
\hline CIPP & $\leftarrow$ & Knowledge sharing & 0.093 & 0.016 & 5.886 & $* * *$ & W27 \\
\hline CIPP & $\leftarrow$ & Leadership support & 0.129 & 0.01 & 12.272 & $* * *$ & W28 \\
\hline CIPP & $\leftarrow$ & Effective communication & 0.213 & 0.028 & 7.658 & $* * *$ & W29 \\
\hline CIPP & $\leftarrow$ & $\begin{array}{c}\text { Collaborative innovation } \\
\text { willingness }\end{array}$ & 0.143 & 0.015 & 9.515 & $* * *$ & W31 \\
\hline CIPP & $\leftarrow$ & Collaborative innovation & 0.455 & 0.054 & 8.413 & $* * *$ & W32 \\
\hline CIPP & $\leftarrow$ & Resource dependence & 0.045 & 0.013 & 3.357 & $* * *$ & W36 \\
\hline
\end{tabular}

Note: ${ }^{* * *}$ It means significant at $1 \%$.

The results in the table are not standardized results. Table 4 shows the result of the standardized, intuitive parameter estimates and convenient parameters for size comparison.

Table 4. Parameter estimation results of standardized coefficients.

\begin{tabular}{|c|c|c|c|}
\hline & & & Estimate \\
\hline $\begin{array}{c}\text { Collaborative innovation } \\
\text { willingness }\end{array}$ & $\leftarrow$ & Resource dependence & 0.777 \\
\hline $\begin{array}{c}\text { Collaborative innovation } \\
\text { willingness }\end{array}$ & $\leftarrow$ & Incentive mechanism & 1.103 \\
\hline $\begin{array}{c}\text { Collaborative innovation } \\
\text { willingness }\end{array}$ & $\leftarrow$ & Benefit distribution & 4.179 \\
\hline Knowledge sharing & $\leftarrow$ & Organizational climate & 1.232 \\
\hline Knowledge sharing & $\leftarrow$ & $\begin{array}{c}\text { Collaborative innovation } \\
\text { willingness }\end{array}$ & 0.007 \\
\hline CIPP & $\leftarrow$ & Benefit distribution & 6.158 \\
\hline CIPP & $\leftarrow$ & Organizational climate & 0.747 \\
\hline CIPP & $\leftarrow$ & Knowledge sharing & 0.736 \\
\hline CIPP & $\leftarrow$ & Leadership support & 1.651 \\
\hline CIPP & $\leftarrow$ & Effective communication & 1.604 \\
\hline CIPP & $\leftarrow$ & $\begin{array}{c}\text { Collaborative innovation } \\
\text { willingness }\end{array}$ & 0.368 \\
\hline CIPP & $\leftarrow$ & Collaborative innovation & 4.052 \\
\hline CIPP & $\leftarrow$ & Resource dependence & 0.45 \\
\hline
\end{tabular}

From Tables 3 and 4, we can conclude that all parameters passed the inspection under the condition of a 5\% significant level, which supports H1-H13.

To find the factors that affected the performance of collaborative innovation projects, we determined the total standardization coefficient that affected the performance, as shown in Table 5.

From Table 5, we can conclude that the influence of the distribution of interest factors was the largest among the nine factors affecting performance, and its total coefficient value was 7.716. The distribution of interest factors exerted an influence on the performance of collaborative innovation projects in three ways. 
Table 5. Total impact of standardized coefficients.

\begin{tabular}{cccc}
\hline & $\begin{array}{c}\text { Collaborative } \\
\text { Innovation } \\
\text { Willingness }\end{array}$ & $\begin{array}{c}\text { Knowledge } \\
\text { Sharing }\end{array}$ & $\begin{array}{c}\text { Collaborative } \\
\text { Innovation Project } \\
\text { Performance }\end{array}$ \\
\hline Benefit distribution & 4.179 & 0.03 & 7.716 \\
Resource dependence & 0.777 & 0.006 & 0.739 \\
Incentive mechanism & 1.103 & 0.008 & 0.411 \\
Organizational climate & 0 & 1.232 & 1.654 \\
Collaborative innovation & 0 & 0.007 & 0.373 \\
willingness & 0 & 0 & 1.604 \\
Effective communication & 0 & 0 & 1.651 \\
Leadership support & 0 & 0 & 0.736 \\
Knowledge sharing & 0 & 0 & 4.052 \\
Collaborative innovation & 0 & 0 & 0 \\
CIPP & & & \\
\hline
\end{tabular}

First, the interest distribution directly affected the performance of collaborative innovation projects, and the coefficient was 6.158. Second, the interest distribution indirectly affected the performance by directly influencing the collaborative innovation willingness, and the coefficient was $4.179 \times 0.368$. Third, the interest distribution indirectly affected performance by directly influencing willingness and knowledge sharing, and the coefficient was $4.179 \times 0.007 \times 0.736$. The latter two were indirect effects.

The rest were similar; the dependence on resources had direct and indirect effects on the performance of collaborative innovation projects, and the total coefficient was 0.739 ; the incentive mechanism had an indirect influence on performance, and the coefficient was 0.411; organizational climate had direct and indirect effects on performance, and the total coefficient was 1.654; collaborative innovation willingness had direct and indirect effects on performance, and the total coefficient was 0.373 ; effective communication had a direct influence on performance, and the coefficient was 1.604; support from leadership had a direct influence on performance, and the coefficient was 1.651; knowledge sharing had a direct influence on performance, and the coefficient was 0.736; and collaborative innovation ability had a direct influence on performance, and the coefficient was 4.052.

\subsubsection{Model Fitting Evaluation}

This study distinguished the model fitting effect through the fitting degree of AMOS output indicators; Table 6 shows the main fitting indicators.

Table 6. Model fit index.

\begin{tabular}{lcccccc}
\hline Fit Index & CMIN/DF & RMSEA & RMR & CFI & NFI & IFI \\
\hline Results & 2.238 & 0.072 & 0.034 & 0.924 & 0.912 & 0.928 \\
Ideal & $\leq 2$ & $\leq 0.05$ & $\leq 0.05$ & $\geq 0.9$ & $\geq 0.9$ & $\geq 0.9$ \\
standard & Acceptable & Acceptable & Good & Good & Good & Good \\
Evaluate & Acced
\end{tabular}

From Table 5, among the fitting indicators in SEM that affected the performance of collaborative innovation projects, the value of chi-square degrees of freedom was 2.238, which is slightly higher than the ideal value of 2; however, less than 3 is acceptable. The RMSEA value was 0.072 , which is higher than the ideal value of 0.05 , but values in the range of $0.05-0.08$ are acceptable. The RMR value was 0.034 , which is less than the ideal standard of 0.05 . The other indices of CFI, NFI, and IFI were all higher than the ideal value of 0.9 , indicating that the fitting degree of the model was good.

From the above analysis, we can conclude that the SEM fitting degree we established was good, which indicates that the construction of the whole model was effective. 


\section{Conclusions, Contributions, and Future Research}

\subsection{Conclusions and Theoretical Contributions}

This study started from the perspective of collaborative innovation project performance and tried to outline the comprehensive and systematic action mechanism that affects performance. The factors that affect performance were divided into tangible and intangible elements, and a comprehensive model that included nine factors and collaborative innovation project performance was constructed. It also analyzed the specific influence mechanism, and an empirical study with a structural equation model was undertaken. The nine factors were interest distribution, resource dependence, incentive mechanism, organizational climate, collaborative innovation willingness, effective communication, leadership support, knowledge sharing degree, and collaborative innovation ability.

The research conclusion is not only helpful for deepening the related research on the impact of collaborative innovation project performance, it is also a useful supplement to the related theoretical research involving the nine elements and is helpful for boosting the practical needs of collaborative innovation project management.

Through theoretical analysis and empirical research, the main conclusions and theoretical contributions were as follows:

(1) The nine factors had a significant positive impact on the performance of collaborative innovation projects, where benefit distribution and collaborative innovation ability were the two most important factors.

In the SEM model with the nine factors of collaborative innovation project performance, the standardized path coefficients of benefit distribution, resource dependence, incentive mechanism, organizational climate, collaborative innovation willingness, effective communication, leadership support, knowledge sharing degree, and collaborative innovation ability on performance were $7.716,0.739,0.411,1.654,0.373,1.604,1.651,0.736$, and 4.052, respectively, and they were all significant.

This conclusion is similar to those of Berbegal [57], Shan [28], and Bstieler [40]. However, different from previous studies, this study combined tangible and intangible elements in a systematic and comprehensive analysis. The results further extend previous research and show that the performance of collaborative innovation projects is affected by both tangible and intangible elements. Therefore, the success of collaborative innovation projects depends on comprehensive and systematic management to a certain extent. It is an overall multidimensional arrangement, including the specific way of distributing interests and intangible elements, such as the organizational atmosphere.

(2) Benefit distribution, resource dependence, organizational climate, and collaborative innovation affected the project performance not only directly but also indirectly by influencing other factors.

The direct path coefficient of benefit distribution in project performance was 7.716, the indirect path coefficient in collaborative innovation willingness was $4.179 \times 0.368$, and the indirect path coefficient in collaborative innovation-willingness-knowledge sharing degree on project performance was $4.179 \times 0.007 \times 0.736$.

This shows that the influencing factors of project performance, in addition to having a direct role, also played an indirect role. It shows that when carrying out collaborative innovation projects, we should pay attention not only to the direct role of factors but also to the corresponding indirect role path.

This conclusion is similar to those of Gendreau [49], Yorusaf [53], and Liu [60]. The difference is that most of the conclusions in the previous studies were about the direct and indirect effects of certain factors on performance. This present result was based on the consideration of the impact of multiple factors on project performance and identified that some have a direct impact, some have an indirect impact, and some have both. This shows that the paths of factors in project performance were not the same, but each had its own specific trajectory.

(3) The incentive mechanism had no direct effect on project performance but indirectly affected project performance by influencing collaborative innovation willingness. Collabo- 
rative innovation willingness affected project performance directly, as well as indirectly, through knowledge sharing. At the same time, it was affected by the incentive mechanism and resource dependence.

This shows that the influencing factors of collaborative innovation projects not only affected project performance but also had interaction paths with each other. This conclusion is an extension of the previous single study. It shows that the boundaries of different elements in the mechanism of collaborative innovation project performance are different.

The above conclusion is more applicable to China because it is based on China's CIP. If it is used in the field of CIP in other countries, appropriate adjustments should be made according to the specific situation.

\subsection{Management Contribution}

Against the background of sustainable and high-quality development, considering the practical needs of collaborative innovation project management, this paper puts forward the following suggestions:

(1) Establish a comprehensive and systematic management concept.

This study examined the impact of nine factors on collaborative innovation project performance: benefit allocation, resource dependence, incentive mechanism, organizational climate, collaborative innovation willingness, effective communication, leadership support, knowledge sharing degree, and collaborative innovation ability. The results show that these nine factors have a significant positive impact on performance.

These nine aspects involve the environment, atmosphere, resources, system, leadership, and so on, and include both tangible and intangible elements.

This shows that it is necessary to establish a comprehensive and systematic management concept for collaborative innovation project management. At the beginning of the project, there should be an effort to consider all aspects and formulate corresponding coping strategies. During the project, managers should assess the actual situation in order to dynamically adjust the management strategy.

(2) Use targeted management strategies.

The results also show that some factors affect project performance not only directly but also indirectly by influencing other factors. For example, benefit distribution had a direct impact on project performance, an indirect impact by influencing collaborative innovation willingness, and an indirect impact by influencing knowledge sharing degree by influencing collaborative innovation willingness. In addition, resource dependence, organizational climate, and collaborative innovation willingness had both direct and indirect effects on project performance.

This shows that collaborative innovation project management should use a more refined management strategy. It is necessary to implement specific and targeted management strategies in combination with different specific elements and consider their paths to the results.

(3) Form a balanced management pattern.

From the results, we can see that nine factors had a significant impact on performance, but their impact mechanisms were not the same. Some factors only had a direct impact on performance, some only had an indirect impact, some had both, and there was a certain degree of mechanism between the factors. That is, some factors could play an independent role, and some factors needed to be combined with others to enhance their role. This is a kind of balanced and dynamic thinking. Therefore, in the management of collaborative innovation projects, we must form a balanced management idea and pattern to produce the best benefit.

\subsection{Research Limitations and Prospects}

From a theoretical perspective, this study was based on related research, and the conclusion contributes to research on collaborative innovation projects and the nine influencing factors and can enrich the theoretical literature in the corresponding fields. 
In practice, this study carried out an empirical analysis based on a certain number of collaborative innovation projects. The management suggestions based on the conclusions can boost the high-quality management needs of collaborative innovation projects.

At the same time, the study also has some limitations and prospects.

(1) The final effective sample data used in this study was taken from 199 collaborative innovation projects; this involved many regional industries. However, in practice, the scale of such projects is huge, so it is still worth expanding the sample size for further research.

(2) The sample of this study was only from China, and subjects from different countries may have different experiences [67]. Therefore, in the future, the conclusions could be applied to other countries with different cultural backgrounds, which will verify whether our conclusions can be supported.

(3) In practice, a collaborative innovation project is a complex and diverse dynamic process. If the project performance variables can be set as dynamic variables to carry out research, it will be more reasonable in theory and more in line with the characteristics of such projects in practice.

Author Contributions: L.L. conceived and designed the study. H.L. wrote the draft of the manuscript. Z.L. performed data analysis. Y.L. and L.L. revised the manuscript. All authors have read and agreed to the published version of the manuscript.

Funding: This study was supported by the National Natural Science Foundation of China (nos. 71473076 and 71573078).

Institutional Review Board Statement: Not applicable.

Informed Consent Statement: Not applicable.

Data Availability Statement: Data generated or analyzed during the study are available from the corresponding author by request.

Conflicts of Interest: The authors declare no conflict of interest.

\section{References}

1. Sun, Q.; Zhou, X.; Economics, S.O.; University, P. Scientific-Technological Innovation and High-Quality Economic Development. J. Peking Univ. Philos. Soc. Sci. 2020, 57, 140-149.

2. Website of National Bureau of Statistics of China. Available online: http:/ / www.tjcn.org/tigb/ (accessed on 4 March 2021).

3. Arant, W.; Fornahl, D.; Grashof, N.; Hesse, K.; Soellner, C. University-industry collaborations-The key to radical innovations? Rev. Reg. Res. 2019, 39, 119-141. [CrossRef]

4. Lin, L.; Fan, F.; Liu, S. A Multi-stage and Dynamic Distribution of the Benefits for Collaborative Innovation Project. Sci. Technol. Prog. Policy 2017, 3, 21-31.

5. Wu, A.H.; Wang, Z.; Chen, S. Impact of specific investments, governance mechanisms and behaviors on the performance of cooperative innovation projects. Int. J. Proj. Manag. 2017, 35, 504-515. [CrossRef]

6. Fernandes, G.; Barbosa, J.; Pinto, E.B.; Araújo, M.; Machado, R.J. Applying a Method for Measuring the Performance of University-Industry R\&D Collaborations: Case Study Analysis-ScienceDirect. Procedia Comput. Sci. 2019, 164, 424-432.

7. López, S.; Astray, B.P.; Pazos, D.R.; Calvo, N. Are firms interested in collaborating with universities? An open-innovation perspective in countries of the South West European Space. Serv. Bus. 2015, 9, 637-662. [CrossRef]

8. Kafouros, M.; Love, J.H.; Ganotakis, P.; Konara, P.; Phillips, F. Experience in R\&D collaborations, innovative performance and the moderating effect of different dimensions of absorptive capacity. Technol. Forecast. Soc. Chang. 2020, 150, 119757.

9. Azagracaro, J.M.; Tijssen, R.; Yegrosyegros, A. Measuring macro-level effects of the global economic recession on universityindustry research cooperation. In Proceedings of the 21st International Conference on Science and Technology Indicators-STI, València, Spain, 14-16 September 2016.

10. He, C.; Wu, J.; Zhang, Q. Research leadership flow determinants and the role of proximity in research collaborations. J. Assoc. Inf. Sci. Technol. 2020, 71, 1341-1356. [CrossRef]

11. Fernandes, G.; Pinto, E.B.; Araújo, M.; Machado, R.J. The roles of a Programme and Project Management Office to support collaborative university-Industry R\&D. Total Qual. Manag. Bus. Excell. 2020, 31, 583-608.

12. Liu, Y.; Business, S.O.; University, J. Incentive Mechanism for Collaborative Innovation of Industry-University form the Benefit Distribution Perspective. J. Syst. Manag. 2016, 3, 35-46.

13. Fernandes, G.; Araújo, M.; Andrade, R.; Pinto, E.B.; Tereso, A.; Machado, R.J. Critical factors for benefits realisation in collaborative university-industry R\&D programs. Int. J. Proj. Organ. Manag. 2020, 12, 1-10. 
14. Freitas, I.; Verspagen, B. The motivations, institutions and organization of university-industry collaborations in the Netherlands. J. Evol. Econ. 2017, 27, 379-412. [CrossRef]

15. Maurer, I. How to build trust in inter-organizational projects: The impact of project staffing and project rewards on the formation of trust, knowledge acquisition and product innovation-ScienceDirect. Int. J. Proj. Manag. 2010, 28, 629-637. [CrossRef]

16. Lee, K.J.; Ohta, T.; Kakehi, K. Formal boundary spanning by industry liaison offices and the changing pattern of universityindustry cooperative research: The case of the University of Tokyo. Technol. Anal. Strateg. Manag. 2010, 22, 189-206. [CrossRef]

17. Kamuriwo, D.S.; Baden-Fuller, C. Knowledge integration using product R\&D outsourcing in biotechnology. Res. Policy 2016, 45, 1031-1045.

18. $\mathrm{Wu}, \mathrm{A}$. The mediating roles of governance mechanisms and knowledge transfer on the relationship between specific investments and cooperative innovation performance. Technol. Anal. Strateg. Manag. 2016, 28, 217-230. [CrossRef]

19. Han, J. Technology Commercialization through Sustainable Knowledge Sharing from University-Industry Collaborations, with a Focus on Patent Propensity. Sustainability 2017, 9, 1808. [CrossRef]

20. Yu, S.; Yuizono, T. A Proximity Approach to Understanding University-Industry Collaborations for Innovation in Non-Local Context: Exploring the Catch-Up Role of Regional Absorptive Capacity. Sustainability 2021, 13, 3539. [CrossRef]

21. Lee, K.J. Development of boundary-spanning organisations in Japanese universities for different types of university-Industry collaborations: A resource dependence perspective. Asian J. Technol. Innov. 2014, 22, 204-218. [CrossRef]

22. Hoppmann, J. Hand in hand to Nowhereland? How the resource dependence of research institutes influences their co-evolution with industry. Res. Policy 2021, 50, 41-45. [CrossRef]

23. Institute, P.M. A Guide to the Project Management Body of Knowledge (Pmbok Guide) Fifth Ed.: Official Korean Translation. Proj. Manag. J. 2013, 44, 51-61.

24. Xu, J.Z.; Zhao, Y.N.; Zhu, X.Y.; Wang, M.M. Research on Evaluation of Collaborative Innovation Ability of Equipment Manufacturing Enterprises Based on Factor Analysis. In Proceedings of the 2017 International Conference on Management Science and Engineering (ICMSE), Nomi, Japan, 17-20 August 2017; pp. 321-327.

25. An, X.M.; Guo, M.J.; Wei, W. Research on the Ability Construction of Collaborative Innovation Community in the Integration and Sharing Project of Government Information System. Inf. Stud. Theory Appl. 2019, 42, 80-86.

26. Hong, J.; Zheng, R.; Deng, H.; Zhou, Y. Green supply chain collaborative innovation, absorptive capacity and innovation performance: Evidence from China. J. Clean. Prod. 2019, 241, 1-13. [CrossRef]

27. Zhang, L. Research on Collaborative Innovation Network Mechanism of General Aviation Enterprises Based on Complex Network. IOP Conf. Ser. Earth Environ. Sci. 2021, 632, 52-99. [CrossRef]

28. Shan, H.; Li, Y.; Shi, J. Influence of Supply Chain Collaborative Innovation on Sustainable Development of Supply Chain: A Study on Chinese Enterprises. Sustainability 2020, 12, 2978. [CrossRef]

29. Tseng, F.-C.; Huang, M.-H.; Chen, D.-Z. Factors of university-industry collaboration affecting university innovation performance. J. Technol. Transf. 2020, 45, 560-577. [CrossRef]

30. Kobarg, S.; Stumpf-Wollersheim, J.; Welpe, I.M. University-industry collaborations and product innovation performance: The moderating effects of absorptive capacity and innovation competencies. J. Technol. Transf. 2018, 43, 1696-1724. [CrossRef]

31. Collins, C.J.; Smith, K.G. Knowledge exchange and combination: The role of human resource practices in the performance of high-technology firms. Acad. Manag. J. 2006, 49, 544-560. [CrossRef]

32. Pang, S.; Bao, P.; Hao, W.; Kim, J.; Gu, W. Knowledge Sharing Platforms: An Empirical Study of the Factors Affecting Continued Use Intention. Sustainability 2020, 12, 2341. [CrossRef]

33. Zhang, H.B.; Yang, B.; Zhang, S.J. Knowledge Sharing Mechanism in Innovation Team of College Teachers-From the Perspective of Knowledge Convening and Fermenting. J. High. Educ. Financ. 2019, 22, 4-9.

34. Doan, M.; Doan, H. Knowledge Sharing, Innovation and Firm Performance: Evidence from Turkey. EconStor Open Access Artic. 2020, 33, 36-52.

35. Rahmi, D.Y.; Indarti, N. Examining the relationships among cognitive diversity, knowledge sharing and team climate in team innovation. Team Perform. Manag. 2019, 25, 299-317. [CrossRef]

36. Than, S.T.; Nguyen, C.H.; Tran, T.Q.; Le, P.B. Building Competitive Advantage for Vietnamese Firms: The Roles of Knowledge Sharing and Innovation. Int. J. Bus. Adm. 2019, 10, 1-13. [CrossRef]

37. Pirola-Merlo, A. Agile innovation: The role of team climate in rapid research and development. J. Occup. Organ. Psychol. 2010, 83, 1075-1084. [CrossRef]

38. Ahmed, R.; Anantatmula, V.S. Empirical Study of Project Managers Leadership Competence and Project Performance. Eng. Manag. J. 2017, 29, 189-205. [CrossRef]

39. Pham, H.; Kim, S.-Y. The effects of sustainable practices and managers' leadership competences on sustainability performance of construction firms. Sustain. Prod. Consum. 2019, 20,1-14. [CrossRef]

40. Bstieler, L.; Hemmert, M.; Barczak, G. The changing bases of mutual trust formation in inter-organizational relationships: A dyadic study of university-industry research collaborations. J. Bus. Res. 2017, 74, 47-54. [CrossRef]

41. Schreiner, M.; Kale, P.; Corsten, D. What really is alliance management capability and how does it impact alliance outcomes and success? Strateg. Manag. J. 2010, 30, 1395-1419. [CrossRef]

42. Adiguzel, Z. Relationships among Leader Effectiveness, Learning Orientation, Effective Communication, Team Creativity and Service Innovation in the Service Sector. Bus. Econ. Res. J. 2019, 10, 131-148. 
43. Iswanti, M.E.; Rahmanto, A.; Muktiyo, W. Leader's Influence and Communication Styles on the Culture of Innovation in FIFGROUP. Int. J. Multicult. Multireligious Underst. 2019, 5, 190. [CrossRef]

44. Bruneel, J.; D'Este, P.; Salter, A. Investigating the factors that diminish the barriers to university-industry collaboration. Res. Policy 2010, 39, 858-868. [CrossRef]

45. He, Y.T.; Xie, F. Research on the incentive mechanism of the industry-university-institute collaborative innovation based on the quantum game theory. Syst. Eng. Theory Pract. 2019, 39, 1435-1448.

46. Xiong, Z.; Wang, P.; Wu, C. How to encourage innovation failure knowledge sharing in virtual research organization: An incentive mechanism based on game theory. Comput. Math. Organ. Theory 2021, 23, 1-21.

47. Wu, J.; Che, X.J.; Sheng, Y.X.; Chen, L.; Shi, Q.F. Study on Government-industry-university-institute Collaborative Innovation Based on Tripartite Evolutionary Game. Chin. J. Manag. Sci. 2019, 27, 162-173.

48. Vaaland, T.I.; Hakansson, H. Exploring interorganizational conflict in complex projects. Ind. Mark. Manag. 2003, 32, 127-138. [CrossRef]

49. Gendreau, E.; Benhayoun-Sadafiyine, L.; Dain, M.; Summers, J. Ranking absorption practices of knowledge for collaborative innovation: Which is the Ideal multi criteria decision method. In Proceedings of the 22nd International Conference on Engineering Design(ICED19), Delft, The Netherlands, 5-8 August 2019; pp. 2337-2346.

50. Allmendinger, M.P.; Berger, E.S.C. Selecting Corporate Firms for Collaborative Innovation: Entrepreneurial Decision Making in Asymmetric Partnerships. Int. J. Innov. Manag. 2019, 24, 2050003. [CrossRef]

51. Abhari, K.; Davidson, E.J.; Xiao, B. Collaborative innovation in the sharing economy: Profiling social product development actors through classification modeling. Internet Res. 2019, 3, 1313-1324. [CrossRef]

52. Wang, H.; Wang, S.; Yang, C.F.; Jiang, S.N.; Li, Y.J. Resource Price Fluctuations, Resource Dependence and Sustainable Growth. Sustainability 2019, 11, 6371. [CrossRef]

53. Yousaf, U.; Pakistan, P.L. Knowledge Management in the light of Resource-Based View, Resource Dependence View, and Population Ecology View. Int. J. Sci. Basic Appl. Res. 2019, 48, 58-77.

54. Merx-Chermin, M.; Nijhof, W.J. Factors influencing knowledge creation and innovation in an organisation. J. Eur. Ind. Train. 2005, 29, 135-147. [CrossRef]

55. Narula, R. R\&D Collaboration by SMEs: Some Analytical Issues and Evidence. In Cooperative Strategies and Alliances; Emerald Group, Pergamon Press: London, UK, 2002; Volume 101, pp. 439-460.

56. Sivadas, E.; Dwyer, F.R. An Examination of Organizational Factors Influencing New Product Success in Internal and AllianceBased Processes. J. Mark. 2000, 64, 31-49. [CrossRef]

57. Berbegal-Mirabent, J.; Sanchez Garcia, J.L.; Enrique Ribeiro-Soriano, D. University-Industry partnerships for the provision of R\&D services. J. Bus. Res. 2015, 68, 1407-1413.

58. Li, Y.; Huang, J.; Guo, H.; Wang, Z. Research on incentive mechanism of benefit distribution in collaborative innovation of industry alliance. MATEC Web Conf. 2021, 336, 09008. [CrossRef]

59. Patra, P. Distribution of profit in a smart phone supply chain under Green sensitive consumer demand. J. Clean. Prod. 2018, 192, 608-620. [CrossRef]

60. Liu, L.; Liao, W.Z. Optimization and profit distribution in a two-echelon collaborative waste collection routing problem from economic and environmental perspective. Waste Manag. 2021, 120, 400-414. [CrossRef]

61. Huang, M.H.; Chen, D.Z. How can academic innovation performance in university-industry collaboration be improved? Technol. Forecast. Soc. Chang. 2017, 123, 210-215. [CrossRef]

62. Steinmo, M. Collaboration for Innovation: A Case Study on How Social Capital Mitigates Collaborative Challenges in UniversityIndustry Research Alliances. Ind. Innov. 2015, 22, 597-624. [CrossRef]

63. Xu, X.; Jiang, L.; Wang, H. How to build your team for innovation? A cross-level mediation model of team personality, team climate for innovation, creativity, and job crafting. J. Occup. Organ. Psychol. 2019, 92, 848-872. [CrossRef]

64. Al-Refaie, A.; Al-Tahat, M. Effects of Knowledge Management and Organizational Learning on Firm Performance. J. Nat. Sci. Sustain. Technol. 2014, 8, 369-390.

65. Wen, Q.; Qiang, M. Project Managers' Competences in Managing Project Closing. Proj. Manag. J. 2019, 50, 361-375. [CrossRef]

66. Podsakoff, P.M.; MacKenzie, S.B.; Lee, J.Y.; Podsakoff, N.P. Common method biases in behavioral research: A critical review of the literature and recommended remedies. J. Appl. Psychol. 2003, 88, 879-903. [CrossRef]

67. Gao, B.; Li, X.; Liu, S.; Fang, D. How power distance affects online hotel ratings: The positive moderating roles of hotel chain and reviewers' travel experience. Tour. Manag. 2018, 65, 176-186. [CrossRef] 